\title{
Ortega, Ricoeur y la razón narrativa
}

José Mendívil Macías Valadez Universidad de Guanajuato, México

Resumen

Pretendo aquí mostrar la pertinencia actual del pensamiento de José Ortega y Gasset, precisamente haciendo una comparación con una vía contemporánea paralela en muchos sentidos, la del filósofo francés Paul Ricoeur. La estrategia de caminar desde el presente hacia el pasado de la noción narrativa del sujeto nos permite tener a la vista la actualidad y la profundidad de algunas de las intuiciones del pensador español.

Palabras clave: identidad narrativa, ética, historicidad.

\section{Abstract}

Throughout this article I will discuse the current relevance of Jose Ortega y Gasset's thought, precisely for its comparison with the french philosopher Paul Ricoeur's thought, which is a more contemporary approach in many different ways. This essay treats to analyse, from present to past, the narrative of subject. That will allow us to have at sight the relevance and deepness of the Spanish philosopher's thought und his intuitions.

Keywords: narrative identity, ethics, historicity. 


\section{La experiencia humana del tiempo en Ricoeur}

D ara Ricoeur, la temporalidad es una estructura inevitable de la 1 existencia en la medida en que somos seres en el tiempo, con una forma de vida que accede al lenguaje mediante la narratividad. Esto significa que la diferencia entre la historia verdadera y el relato de ficción no es irreductible, puesto que existe una reciprocidad entre la narratividad y la temporalidad; además, el sujeto se construye en esta temporalidad y en esta narratividad. Somos seres humanos gracias al lenguaje, y el lenguaje narra nuestro acaecer en el tiempo.

Somos historicidad porque somos seres sociales y temporales, los acontecimientos históricos hacen progresar una historia susceptible de ser contada. Un acontecimiento histórico se diferencia de un acontecimiento físico precisamente en que puede ocupar una posición en un relato. El acontecimiento histórico tiene su correlato en una trama. Una historia (story) describe una serie de experiencias y de acciones llevadas a cabo por algunos personajes reales o imaginarios que son representados en situaciones cambiantes o que reaccionan al cambiar éstas. El desarrollo de una historia nos impele a seguir hacia delante, y respondemos a dicho impulso creándonos expectativas sobre el comienzo y el final de todo el proceso; el "final" de la historia es el polo de atracción de todo el proceso, que a través de peripecias, adversidades o contingencias mantiene nuestro interés y atención.

El tiempo de todo relato es, sin embargo, público, es el tiempo colectivo de los agentes - actantes en su sentido más técnicoo personajes en interacción con el mundo. Aquí se da la vinculación entre el mundo y nuestras posibilidades de acción, es el lugar de la acción y de la pasión. El relato tiene, además, una dimensión episódica de instantes que se explican, y una dimensión configurativa de secuencias y figuras que logran la elaboración de totalidades 
significativas a partir de acontecimientos dispersos, de modo que toda la trama pueda abarcarse con un solo pensamiento. Mientras que Heidegger pensó, en Ser y tiempo, la relación entre nuestro ser finito o ser para la muerte y la historicidad, no desarrolló ni estudió de manera significativa el estrato narrativo y público de la historia, por ello, para Ricoeur, Heidegger se limitó a un carácter "subjetivista y monádico" de la historicidad. Nociones como la de "herencia", "repetición" de un destino o "tradición" de un pueblo no fueron, por tanto, comprendidas de manera adecuada.

La repetición narrativa, la ojeada a nuestro pasado más propio, consistiría en leer el final en el comienzo de nuestra historia, así como el comienzo en el final, recuperando nuestras posibilidades más propias tal como las heredamos del pasado. De este modo, la trama no sitúa la acción humana sólo "en" el tiempo, sino en la memoria. En la narración se daría un "retorno al origen", Ulises y su viaje de ida y vuelta aparecen como un modelo paradigmático de esta experiencia, así como las Confesiones de Agustín, las de Rousseau y El tiempo recobrado de Proust. De esta forma, la vida debe verse como el proceso de convertirnos en lo que somos; la visión desde el final de una vida como el reconocimiento de nuestro pasado y de nuestro presente es una "repetición liberadora", pero también habría que incluir la actitud de afrontar el futuro con decisión. Esto es lo que Heidegger llamaba "destino", pero ahora dentro de una visión menos sombría, menos solipsista y más vital, aunque reconociendo, sin embargo, que la consideración acerca de la muerte es inherente a cualquier meditación acerca de la historia, pues la historia es ante todo de aquéllo que ya no están y son rememorados por el relato. La repetición narrativa acaba siendo, en conclusión, la unión primordial del tiempo y el relato. 


\section{La identidad narrativa}

En la tercera parte de Tiempo y narración, Ricoeur concluye que el lugar de la identidad narrativa, es decir, de aquella identidad que el sujeto humano alcanza mediante la función narrativa, se encuentra en la intersección del tiempo histórico, sujeto al calendario, y del tiempo de la ficción, abierto a variaciones imaginativas ilimitadas. De este modo se abre la posibilidad de una hermenéutica de la "comprensión de sî" o de uno mismo como relato. Es en esta interpretación del "sí mismo" en donde la función narrativa cumple un papel central, y que nos lleva desde las teorías lingüísticas hasta la ética y la política, pasando por la reflexión acerca de la historicidad y de la ficción. El desarrollo más completo de estas ideas se encuentra en la obra titulada Si mismo como otro, que considero la obra más profunda y lograda de Ricoeur en cuanto a la consecución de una teoría narrativa del sujeto.

La posibilidad de integrar el relato histórico y el de ficción se da precisamente en el campo de esta identidad narrativa, pero también el paso del punto de vista meramente descriptivo al prescriptivo y normativo. La ipseidad y la permanencia del sujeto en el tiempo tienen que ver con la continuidad establecida del carácter en cuanto conjunto de signos distintivos que permiten identificar a un individuo humano, y con la "palabra dada" o mantenida en la promesa, que nos obliga a permanecer para sostener un compromiso. El carácter y el compromiso requerirían de "disposiciones duraderas" en las que reconocemos a una persona, en ellos reside nuestra identificación con valores, normas o ideales en los que la persona y la comunidad se reconocen, y que forman una parte central de nuestra identidad. Por ello, afirma Ricoeur que "el carácter tiene una historia" o una dimensión narrativa, tanto en el caso de la identidad personal como, por ejemplo, en el de la identidad nacional de Francia 
o México, que se requieren rasgos diferenciales duraderos de reconocimiento.

La identidad narrativa necesita establecer lo que Dilthey llamaba "conexión de la vida", la cual debe entenderse en los términos de historia de una vida, es decir, en términos de la identidad del personaje en unión con la trama. En la disposición narrativa habría que tomar en cuenta la "disposición de los hechos", constituidos por los términos discordantes que transforman accidentalmente la trama desde el inicio hasta el fin, y los hechos concordantes que forman parte de la configuración de la misma. La "concordancia discordante" consiste en una síntesis de lo heterogéneo, se trata de una estructura inestable que marca la unión del "efecto de contingencia" y del "efecto de necesidad". Los acontecimientos inesperados o sorprendentes se convierten en parte de la historia cuando son comprendidos después desde el punto de vista de su necesidad. La identidad del personaje se comprende trasladando sobre él la operación de construcción de la trama aplicada a la acción narrada, adscribiendo una acción o pasión al agente o actante.

Ricoeur pone a prueba para sus fines los conceptos de "función" y "actante" de Propp, Bremond y Greimas. El personaje de la trama es un actante que opera acciones en un recorrido narrativo, las vidas humanas pueden entenderse como "programas narrativos", a veces en relación polémica. El relato confiere al personaje una iniciativa, la capacidad de realizar una serie de acontecimientos, donde el narrador tiene el poder de determinar el comienzo, el medio y el fin de la acción. De esta correlación entre la acción y el personaje se deriva una dialéctica interna al personaje entre la concordancia y la discordancia. Según la línea de concordancia, el personaje saca su singularidad de la unidad de su vida considerada como la totalidad temporal singular que lo distingue de cualquier otro. Según la línea de discordancia, esta totalidad temporal está amenazada por el efecto de ruptura de los acontecimientos im- 
previsibles que le ocurren. La síntesis de ambas líneas "hace que la contingencia del acontecimiento contribuya a la necesidad en cierto sentido retroactiva de la historia de una vida, con la que se iguala la identidad del personaje. Así el azar se cambia en destino".

La persona, entendida como un personaje del relato, no es una identidad distinta de sus experiencias. Muy al contrario: comparte el régimen de la identidad dinámica propia de la historia narrada. El relato construye la identidad del personaje, que podemos llamar su identidad narrativa, al construir la de la historia narrada. Es la identidad de la historia la que hace la identidad del personaje (Ricoeur, 1996: 147).

\section{La identidad "dramática" de la vida en Ortega}

Afirma José Ferrater Mora, conocedor a fondo de la vida y la obra de Ortega y Gasset, que el centro de la filosofía de éste, es la noción de "vida", y este concepto es, al mismo tiempo:

[...] problema, quehacer, preocupación consigo misma, programa vital, y en último término naufragio (un naufragio del que el hombre aspira a salvarse agarrándose a una tabla de salvación: la cultura). Por eso la vida es también drama y por eso no puede ser una realidad biológica, sino biográfica. El método para acercarse a ella no es el análisis, sino la narración (Ferrater, 1999, t. III: 2662).

En efecto, para Ortega el hombre no es otra cosa sino res dramáti$c a$, más allá de ser una cosa extensa o una cosa pensante.

Pero, ¿qué es la vida? La vida es la realidad radical, e implica, por un lado, la negación de la independencia absoluta del mundo respecto del pensamiento (y viceversa) y, por otro lado, la afirmación de su conjugación: la coexistencia del hombre y el mundo. 
La realidad radical es, en consecuencia, la suma de la existencia humana individual (biográfica) y la circunstancia como espacio antropológico, concebida como el ámbito de los problemas a los que tiene que enfrentarse el Yo.

En la vida radican todas las demás realidades. La vida no "es", es un hacer-se a sí mismo continuamente, un autofabricarse. Ortega no considera al ser como realidad, sino lo contrario, la realidad es anterior al ser, pues fuera del hombre no hay ser, "lo que hay" es más bien algo incompleto, "un intento de ser", con lo que Ortega procede a desmontar la filosofía misma. La realidad no es la naturaleza, ni es la conciencia, sino que es mi vida, la vida de cada cual, la vida humana: "El mundo es lo vivido como tal". De ese modo, el yo es un proyecto de vida:

'La vida es constitutivamente un drama, por que es siempre lucha frenética por conseguir ser de hecho el que somos en proyecto'. 'Pero no se trata de un proyecto ideado... preferido libremente. Este proyecto lo encontramos ya formado al encontrarnos viviendo' (Ortega y Gasset, 1969, t. IV: 77).

Por ello, la razón histórica consiste simplemente en narrar, ella es la única capaz de entender las realidades humanas, porque la contextura de éstas es ser históricas, es historicidad. Ningún hecho aislado explica una realidad histórica, es preciso antes integrarlo en la figura total de un tipo de vida humana para que no sea simplemente un dato muerto. El pensamiento, debido a ello, es una función vital, como la digestión o la circulación de la sangre. La razón lo es de hechos vitales, la razón vital es "vida como razón". 


\section{La historicidad}

En su libro Historia como sistema, publicado originalmente en inglés en 1935, Ortega afirma el carácter hermenéutico de nuestro ser histórico, así como su inevitable carácter vital, lo que nos lleva a su ser narrativo.

El hombre no es cosa ninguna, sino un drama — su vida, un puro y universal acontecimiento que acontece a cada cual y en que cada cual no es, a su vez, sino acontecimiento. Todas las cosas, sean las que fueren, son ya meras interpretaciones que se esfuerza en dar a lo que encuentra (Ortega y Gasset, 1999: 37).

El carácter narrativo de este yo vital, ligado a su circunstancia, implica una desustanciación o descosificación de su ser, lo que le da este carácter fluido, como en aquellas expresiones de Montaigne a lo largo de sus Ensayos, donde se refiere a la condición humana contingente en cuanto inestable, mutable, incierta y abierta al futuro, un individuo inmerso en la temporalidad, el cambio y la accidentalidad. La vida para Ortega es un drama que acontece, "y el 'sujeto' a quien le acontece no es una 'cosa' aparte y antes de su drama, sino que es función de él, quiere decirse que la 'sustancia' sería su argumento. Pero si éste varía, quiere decirse que la variación es 'sustancial'” (Ortega y Gasset, 1999: 40).

No digamos, pues, que el hombre es, sino que vive... la razón, consiste en una narración. Frente a la razón pura físico-matemática hay, pues, una razón narrativa. Para comprender algo humano, personal o colectivo, es preciso contar una historia. Este hombre, esta nación hace tal cosa y es así porque antes hizo tal otro y fue de tal otro modo. La vida sólo se vuelve un poco transparente ante la razón histórica (Ortega y Gasset, 1999: 47). 
Sin embargo, Ortega considera que no hay que lamentar este estado de la condición humana, pues la mudanza de lo humano es "precisamente nuestro privilegio ontológico". Por ello afirma resueltamente que el hombre no tiene naturaleza, sino que tiene historia. La razón histórica:

[...] no una razón extrahistórica que parece cumplirse en la historia, sino literalmente lo que al hombre le ha pasado, constituyendo la sustantiva razón, la revelación de una realidad trascendente a las teorías del hombre y que es él mismo por debajo de sus teorías (Ortega y Gasset, 1999: 59).

Acerca de la relación entre nuestras ideas y nuestras creencias, Ortega considera que el mundo exterior a nosotros no es la realidad primera, sino es una interpretación que da el hombre a esa realidad, y, por lo tanto, es una idea. Son estas ideas las que se consolidan bajo la forma de creencias.

En El tema de nuestro tiempo, así como Nietzsche en La gaya ciencia — donde habla del inevitable perspectivismo-, Ortega considera que la perspectiva es uno de los componentes de la realidad, y anticipándose a la idea gadameriana de la fusión de horizontes hermenéutica afirma:

La versión integral solo se obtiene articulando lo que el prójimo ve con lo que yo veo, y así sucesivamente. Cada individuo es un punto de vista esencial. Yuxtaponiendo las visiones parciales de todos se lograría tejer la verdad omnímoda y absoluta (Ortega y Gasset, 1976: 106).

Puesto que vivir es encontrarse forzado a interpretar nuestra vida, esta vida nuestra aparece como el "intérprete universal”. El pensamiento filosófico siempre ha estado insertado en tradiciones de- 
terminadas, en las que nos hallamos tan sumergidos que aparecen para nosotros como la realidad misma.

En cuanto a la ética, un buen adelanto de nuestras éticas de la alteridad son las afirmaciones siguientes:

Ha sido un error incalculable sostener que la vida, abandonada a sí misma, tiende al egoísmo, cuando es en su raíz y esencia inevitablemente altruista... La vida es el hecho cósmico del altruismo, y existe solo como perpetua emigración del Yo vital hacia lo Otro (Ortega y Gasset, 1976: 82).

\section{Naufragio y destino}

Empezar a comprender al hombre como una realidad en ciernes, in via, nos lleva a la vieja concepción del homo viator; somos sustancialmente peregrinos, los conceptos quietos no nos acomodan ya, y tenemos que pensar con nociones incesantemente en marcha. La conclusión de todo esto es la concepción de la vida como naufragio.

Vivir es encontrarse en un naufragio entre las cosas. No hay más remedio que agarrarse a ellas. Pero ellas son fluidas, indecisas, fortuitas. De aquí que nuestra relación con las cosas sea constitutivamente inseguridad (Ortega y Gasset, 1981: apéndice VII).

Si nuestra vida es ante todo toparse con el futuro, entonces es una actividad que se ejecuta siempre hacia delante; como en el caso de Sartre, somos lo que nos vamos haciendo y lo que vamos proyectando. Pero para Ortega la traducción de nuestra libertad proyectiva en necesidad es a lo que estamos condenados, tenemos que convertir la vida en una creación nuestra, pero aceptando su inexorable circunstancia. Es a lo que se llama "destino", a una reabsorción de nuestra circunstancia contingente (Mendívil, 2004: 
227). Vivir con autenticidad es agarrarse y estrechar con entusiasmo la mano que el universo nos tiende, asumir plenamente esta circunstancia que nos rodea.

José Luis Molinuevo, comentando acerca de esta orteguiana razón narrativa, señala acerca de nuestro autor:

[está] continuando la relación establecida en su juventud entre literatura y vida, reforzándola ahora con su afirmación de que la vida es un género literario. Tanto una cosa como la otra pertenecen a este sentido estético del vivir que recibe Ortega como herencia de los literatos franceses... Ortega recalca en ese momento que la literatura es el punto de vista privilegiado de la vida que habla desde un yo a través de un personaje (2002: 209).

Por ello, la vida de un texto consiste en que es el texto de una vida. Considero que a partir de ambas exposiciones nos tiene que quedar claro, sin necesidad de mayor demostración, la línea de continuidad que cruza a ambos autores. Entre el francés y el español, traspasados por una fuerte formación en la filosofía alemana, existen evidentes lazos. La identidad narrativa o dramática, la historicidad como ineludible y el destino como aquello que cruza entre el azar, la libertad y la necesidad. Podemos ya sorprendernos de semejantes analogías.

\section{Bibliografía}

Ferrater Mora, José, 1999, Diccionario de Filosofía (edición revisada), t. III, Ariel, Barcelona.

Mendívil, José, 2004, Ética y contingencia, Universidad de Guanajuato, México. 
Molinuevo, José Luis, 2002, Para leer a Ortega, Alianza, Madrid.

Ortega y Gasset, José, 1969, Obras completas, t. IV, Revista de Occidente, Madrid.

__, 1976, El tema de nuestro tiempo, Revista de Occidente, Madrid.

—_, 1981, ¿Qué es filosofía?, Apéndice VII, Alianza, Madrid.

__, 1999, Historia como sistema, Alianza, Madrid.

Ricoeur, Paul, 1996, Si mismo como otro (trad. de Agustín Neira), Siglo XXI, México. 